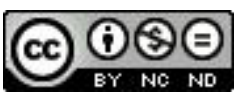

\title{
A Intervenção do Professor em um Ambiente de Modelagem Matemática e a Regulação da Produção Discursiva dos Alunos
}

\section{The Intervention of the Teacher in a Mathematical Modelling Environment and Regulation of the Discursive Production of Students}

\author{
Thaine Souza Santana* \\ Jonei Cerqueira Barbosa**
}

\begin{abstract}
Resumo
Neste artigo, buscamos compreender como o discurso do professor pode regular as produções discursivas dos alunos em um ambiente de Modelagem Matemática. A pesquisa realizada foi de natureza qualitativa e os dados foram coletados por meio de observações e entrevistas. A análise dos dados sugere que os discursos dos alunos foram regulados a partir do que chamamos de discurso procedimental e discurso silenciador, produzidos pelo professor no ambiente de aprendizagem. Neste artigo, definimos e caracterizamos estas noções teóricas. Estes discursos regularam a produção discursiva dos alunos, no que se refere à escolha dos conteúdos matemáticos, dados e hipóteses a serem utilizados por eles na resolução dos problemas propostos.

Palavras-Chave: Modelagem Matemática. Discurso Procedimental. Discurso Silenciador. Intervenção do Professor. Regulação.

\footnotetext{
"Doutoranda do Programa de Pós-Graduação em Ensino, Filosofia e História das Ciências pela Universidade Federal da Bahia (UFBA) e Universidade Estadual de Feira de Santana (UEFS). Endereço para correspondência: Rua Vênus, 572, Jardim Acácia, CEP: 44004-312, Feira de Santana, BA, Brasil.E-mail: thaine_santana@yahoo.com.br

*** Doutor em Educação Matemática pela Universidade Estadual Paulista (UNESP - Rio Claro). Docente do Programa de Pós-Graduação em Ensino, Filosofia e História das Ciências da Universidade Federal da Bahia (UFBA) e Universidade Estadual de Feira de Santana (UEFS) e do Programa de PósGraduação em Educação da UFBA. Endereço para correspondência: Faculdade de Educação - UFBA, Av. Reitor Miguel Calmon, s/n - Campus Canela, CEP 40110-100, Feira de Santana, BA, Brasil. E-mail: jonei.cerqueira@ufba.br
} 


\begin{abstract}
In this paper, we analyze how the teacher's discourses might regulate the discursive productions of students in a mathematical modeling environment. The research was qualitative and data were collected through observations and interviews. Data analysis suggests that students' discourses were regulated by what we named procedural discourse and silencing discourses, produced by the teacher in the learning environment. In this article, we define and characterize these theoretical notions. These discourses regulated the students' discursive production concerning the choice of the mathematical content, data and assumptions they were to use as they solved the problems.
\end{abstract}

Keywords: Mathematical Modeling. Procedural Discourse. Silencing Discourses. Regulation.

\title{
1 Introdução
}

Em diversas práticas sociais, a matemática tem sido utilizada como um instrumento para a abordagem de problemas e situações presentes no cotidiano de vários setores da sociedade. Todavia, no âmbito educacional, os alunos, muitas vezes, não possuem a oportunidade de explorar as relações entre a matemática escolar e os seus usos em situações do dia-a-dia, de outras ciências ou de ambientes de trabalho (ALRØ; SKOVSMOSE, 2006). Em decorrência, esses alunos, nas aulas de matemática, também não têm a oportunidade de explorarem o papel dos modelos matemáticos ${ }^{1}$ na compreensão de problemas do cotidiano, das ciências e das profissões.

Uma das possibilidades de desafiar tal limitação é por meio do desenvolvimento da modelagem matemática em sala de aula, uma vez que esta se constitui como um ambiente de aprendizagem ${ }^{2}$ que pode possibilitar a compreensão de problemas que relacionam a matemática e o cotidiano (BARBOSA, 2003). Nesta direção, alguns estudos apontaram a importância da inserção de situações do dia-a-dia em aulas de matemática por meio da modelagem $^{3}$ (BARBOSA, 2003; CALDEIRA, 2007; FERREIRA; WODEWOTZKI, 2007), enfatizando que o citado ambiente pode proporcionar motivação, preparação dos alunos para utilizar a matemática em diferentes áreas

\footnotetext{
${ }^{1}$ Modelo matemático é aquele que utiliza símbolos matemáticos, como tabelas, gráficos, equações, inequações, assim, empregam conceitos, notações e/ou procedimentos matemáticos (BARBOSA, 2009).

${ }^{2}$ São as condições propiciadas aos alunos para a realização de determinadas atividades (SKOVSMOSE, 2000).

${ }^{3}$ Por vezes, utilizaremos o termo modelagem para nos referirmos à modelagem matemática.
} 
e compreensão do papel sociocultural da matemática.

No cenário de pesquisas no âmbito da Educação Matemática, muitos entendimentos sobre a modelagem têm sido apresentados (BARBOSA, 2006; 2007b; BASSANEZI, 2004; BORBA; MENEGUETTI; HERMINI, 1999). Dentre as diferentes formas de compreender a modelagem, assumimos a compreensão proposta em Barbosa (2006), autor que define a modelagem como um ambiente de aprendizagem no qual os alunos são convidados a indagar e/ou investigar, por meio da matemática, situações provenientes de outras disciplinas ou do dia-a-dia. Porém, acrescentamos, ainda, que essa investigação pode acontecer em situações provenientes de ambientes de trabalho.

Em seus estudos, Skovsmose (2000) argumenta que ambientes que envolvem dados do dia-a-dia oferecem uma diferente condição de comunicação entre o professor e os alunos, uma vez que faz sentido questionar e suplementar as informações dadas pelo docente para o desenvolvimento da tarefa.

Assim, no desenvolvimento da modelagem, diferentes papéis são definidos para o professor e para os alunos, se comparado à tradição da matemática escolar. Por exemplo, os estudantes podem ter mais controle sobre a comunicação na sala de aula, o que, muitas vezes, não acontece em outros ambientes de aprendizagem (ALMEIDA; DIAS, 2004; BARBOSA, 2001).

De modo geral, o que diferencia esse ambiente de outros é o fato de trabalharem com situações externas à matemática e que se constituem como um problema para os alunos. Além disso, nesse ambiente de aprendizagem, o professor pode mediar o desenvolvimento da modelagem pelos alunos, enquanto se espera que eles tenham um papel mais ativo em sua execução (BARBOSA, 2007b; JACOBINI, 2004).

Entretanto, Oliveira (2007) ressalta que o professor, em suas intervenções, pode formatar as ações dos alunos, como na formulação de hipóteses ou escolha de variáveis, controlando demasiadamente o desenvolvimento do ambiente de modelagem, atitude que pode dissolver características de investigação desse ambiente, o que sugere a importância de o professor observar os estilos de comunicação estabelecidos com os alunos em sala de aula (BARBOSA, 2007a).

Sendo assim, o modo como o professor realiza intervenções no ambiente de modelagem pode levar os alunos a terem papel mais ativo (mais autônomo) no desenvolvimento de suas ações, mas também pode levá-los a uma postura mais acomodada. Isso pode gerar dificuldades para os alunos em lidar com situações que exigem sua autonomia e criatividade, levando-os muitas vezes, a 
apenas viabilizar as indicações do professor (LEIB, 2005; MAAB, 2005; OLIVEIRA, 2007).

Maab (2005) argumenta que os alunos podem sentir dificuldades com os problemas abertos, característicos do ambiente de modelagem, os quais exigem mais do que apenas o domínio de conteúdos matemáticos. A autora cita, para ilustrar, que as dificuldades dos alunos podem ser relacionadas à interpretação da situação proposta, à seleção de variáveis necessárias para a resolução da situação-problema ou à escolha do conteúdo matemático adequado para sua resolução.

Tais dificuldades podem ser consequência da maneira como o professor, tradicionalmente, conduz as aulas de matemática, ou seja, desenvolvendo tarefas que exigem dos estudantes estritamente o conhecimento matemático em seu processo de resolução.

Nessa direção, Oliveira (2007), Leib (2005) e Chronaki e Christiansen (2005) discutem que, ao se engajarem nas tarefas ${ }^{4}$ propostas no ambiente de modelagem os alunos, em geral, buscam produzir as ações que são legitimadas pelo professor no desenvolvimento desse ambiente. Sendo assim, o professor pode ter mais ou menos controle sobre as ações dos estudantes no processo de desenvolvimento da modelagem.

Muitas pesquisas têm abordado o papel do professor nas ações dos alunos (ASSIS; TEIXEIRA, 2007; FREUND, 2008; MAULANA et al., 2011), contudo, tais estudos não têm focalizado sobre como as ações dos estudantes, em determinado ambiente de aprendizagem, podem ser decorrentes do como o professor intervém nele.

Maulana et al. (2011) sublinham que a prática do professor em sala de aula pode variar, e tais variações podem levar a mudanças também nas ações dos estudantes. Convergente com esse resultado, Freund (2008) mostra que, mesmo nos casos em que os professores buscam envolver os alunos em processos de investigações, também sinalizam quais são as ações legítimas no ambiente de aprendizagem.

De forma geral, observamos que há, nesses trabalhos, uma discussão sobre o papel do professor na forma como os alunos participam em ambientes de aprendizagem. Justamente, o ponto que aprofundamos neste artigo: o como as intervenções do professor repercutem nas ações produzidas pelos estudantes

\footnotetext{
${ }^{4}$ Aquilo que é apresentado aos alunos para ser analisado e/ou investigado em um ambiente de aprendizagem. As tarefas propostas no ambiente de modelagem são "abertas" e têm a possibilidade de múltiplas soluções.
} 
no ambiente de modelagem. A fim de promover uma melhor compreensão do nosso objetivo, mobilizamos a seguir alguns conceitos da teoria dos códigos elaborada por Basil Bernstein ${ }^{5}$.

\section{0 discurso do professor como regulador na prática de sala de aula}

Nas interações entre professor e alunos, em sala de aula, é possível identificarmos formas de controle sobre o tipo de comunicação considerada legítima ou ilegítima, o que pode ser posto em termos da noção de regulação. Ela refere-se à existência de regras, mobilizada na relação entre alunos e professor, que permitem reconhecer e produzir a comunicação esperada na prática pedagógica ${ }^{6}$ (BERNSTEIN, 2000). A regulação da comunicação é estabelecida por um aparato de princípios, sintetizado na noção de código: "um princípio regulador, tacitamente adquirido, que seleciona e integra os significados relevantes, as formas de realização e seus contextos evocadores" (BERNSTEIN, 2000, p. 202).

O código é o regulador da relação entre contextos e o gerador de princípios que orientam a produção de textos considerados legítimos (aceitos como pertinentes) dentro de cada contexto. Segundo Bernstein (1990), o texto é qualquer representação pedagógica, falada, escrita, visual, espacial ou expressa na postura ou na vestimenta. Em outras palavras, texto é tudo aquilo que comunica algo. Ele é a forma de relação social tornada visível, possível de ser materializada. Somente pelos textos produzidos em determinado contexto, podemos capturar que princípios reguladores foram mobilizados por seus participantes. Neste trabalho, em vez de texto, usaremos a palavra discurso como sinônimo.

No estudo de Silva e Neves (2006), as autoras apresentaram uma situação em sala de aula onde se considerou a indisciplina de parte dos alunos como a manifestação de atos/condutas, que não foram legitimados pelo professor no contexto regulador da prática pedagógica. No caso em questão, observamos

\footnotetext{
${ }_{5}^{5}$ Basil Bernstein foi professor do Instituto de Educação da Universidade de Londres e diretor da Sociological Research Unit. A preocupação de Bernstein era compreender como a distribuição de poder e os princípios de controle são transformados, ao nível do sujeito, em diferentes princípios de organização (BERNSTEIN, 2000). Para tanto, este sociólogo da Educação desenvolveu a Teoria dos códigos, a qual tem despertado o interesse entre pesquisadores da Educação e da Educação Matemática.

${ }^{6}$ São as relações que ocorrem em um determinado contexto social para a produção e reprodução cultural (BERNSTEIN, 2000). No âmbito escolar, a prática pedagógica pode ser compreendida como as relações entre professor e alunos para ensinar e aprender determinados conteúdos (OLIVEIRA, 2010).
} 
que os discursos produzidos eram ilegítimos em relação aos discursos estabelecidos pelo código dominante naquela prática pedagógica. Por outro lado, os atos e condutas manifestados por outra parte dos alunos e legitimados pelo professor, no contexto regulador da sua prática pedagógica, foram tomados como comportamentos de disciplina. A prática pedagógica possui, por assim dizer, um caráter evocativo sobre a legitimidade dos discursos. No caso relatado em Silva e Neves (2006), o professor teve o papel de dar visibilidade aos textos legítimos e ilegítimos produzidos pelos alunos.

Sendo assim, apesar de existir um código dominante para a sala de aula, historicamente legitimado, no qual apenas determinados discursos são considerados legítimos, pode haver a produção de discursos ilegítimos com relação às práticas já consolidadas. Isso pode ocorrer, já que a sala de aula é composta por diferentes sujeitos, que podem realizar diversas ações, inclusive com base em princípios externos à escola (SILVA; NEVES, 2006).

Segundo Bernstein (1990, 2000), para que um aluno revele uma performance legítima, no contexto específico da prática pedagógica, é necessária a aquisição das regras de reconhecimento e de realização para esse contexto. As regras de reconhecimento permitem fazer a distinção entre contextos, por meio da identificação das características específicas de um dado contexto, distinguindo entre os discursos que são considerados legítimos ou não em uma determinada prática pedagógica. Já as regras de realização, elas criam os meios para a produção do discurso legítimo, elas se referem ao como produzir o texto legítimo.

Utilizemos a noção de regras de reconhecimento e realização para o caso relatado em Borba, Meneghetti e Hermini (1999). Os autores trazem uma situação na qual um grupo de alunas reconheceu as expectativas do professor em relação ao ambiente de modelagem, identificando que deveriam utilizar dados e informações extraídas de situações da realidade, porém, não conseguiram produzir o tipo de solução esperado pelo professor. O grupo não relacionou a matemática já estudada com o problema que escolheram; simplesmente, transportaram informações de algum texto externo para a apresentação. Por esta razão, o professor considerou a atividade como um exemplo que não deu certo.

Nossa hipótese é que os alunos, provavelmente, foram socializados com a tradição da matemática escolar, consolidando, assim, a sua forma de participação. Por certo, devem ter adquirido o código legítimo para ela, na qual poderiam ser capazes de agendar seus discursos legítimos e como produzi-los. 
Ao propor um ambiente de modelagem matemática há uma mudança nas regras de reconhecimento e realização. O grupo de alunos abordou dados reais relativos ao problema, porém não elaboraram um problema a ser resolvido por meio da matemática.

Isso sugere que o grupo de alunos não dominava, claramente, as regras de reconhecimento e de realização para uma prática pedagógica baseada em modelagem matemática. Porém, parecem ter agendado princípios legítimos na tradição em que eles foram socializados.

$\mathrm{Na}$ abordagem de Bernstein (1990, 2000), a definição sobre a legitimidade dos discursos não repousa nos participantes de uma prática pedagógica. Como a prática é definida em termos de relação entre os agentes (no caso, alunos e professor), o código detém princípios avaliativos, os quais permitem aos agentes apreciarem a legitimidade do que se comunica à luz daquilo que o contexto social e historicamente evoca. Em suma, podemos dizer que a legitimidade dos discursos repousa entre os participantes de uma prática pedagógica, embora isso não implique em uma relação horizontal entre eles. Como sustentado em Bernstein (1990, 2000), a natureza da relação pedagógica é hierárquica, de acordo com a posição ocupada pelos agentes, o que os leva a possuírem diferentes controles sobre o que é considerado um discurso legítimo ou não.

Na relação pedagógica entre professor e alunos, reconhecidamente o primeiro possui mais controle devido à posição instituída socialmente. Bernstein (2000) usa o termo transmissor para aquele encarregado de controlar a aquisição do código legítimo. Não devemos tomar essa palavra no sentido utilizado por Freire (2003) para caracterizar a educação bancária. Bernstein (2000) a utiliza para posicionar aquele que está numa posição mais favorável para apreciar a legitimidade de algum discurso na prática pedagógica. Para fazê-lo, o teórico apresenta a noção de regras de avaliação para designar a apreciação da consistência entre o discurso produzido por um agente e os princípios constituídos historicamente que regulam a prática pedagógica.

O uso de regras de avaliação na interação comunicacional expressa uma dimensão regulativa da relação entre, por exemplo, alunos e professores. Em Bernstein (1990, 2000), a regulação ocorre entre quaisquer agentes participantes de uma prática pedagógica, conforme sua estrutura hierárquica. Neste artigo, fazemos um recorte e analisamos como os discursos do professor podem regular a produção discursiva dos alunos no ambiente de modelagem. Antes de apresentarmos os dados que utilizamos para sustentar os resultados 
do estudo, descrevemos o contexto e os procedimentos metodológicos.

\section{Contexto}

Os dados utilizados nesta pesquisa foram coletados em uma sala de aula de uma escola da rede estadual baiana, na cidade de Feira de Santana. A turma observada integrava a modalidade EJA (Educação de Jovens e Adultos) ${ }^{7}$, que corresponde ao $1^{\circ}, 2^{\circ}$ e $3^{\circ}$ anos do ensino médio, no qual são desenvolvidas as disciplinas da área de Ciências Exatas. O ambiente de modelagem foi desenvolvido pelo professor Tito $^{8}$ a partir do tema reciclagem de latas de alumínio. A tarefa foi desenvolvida em um dia, durante quatro aulas consecutivas, no turno matutino.

Tito é formado em Licenciatura em Matemática pela Universidade Estadual de Feira de Santana (UEFS). Ele é professor da rede estadual de ensino há três anos, período no qual tem desenvolvido a modelagem em sala de aula, tendo o apoio de um grupo colaborativo, o Grupo Colaborativo em Modelagem Matemática (GCMM) ${ }^{9}$, do qual fazemos parte. Na turma investigada, observamos o grupo de alunos formado por Alice, Mônica, Nany, Stefany e Teti ${ }^{10}$, foi a primeira vez que Tito desenvolveu o ambiente de modelagem. Alice era tímida, porém se mantinha sempre atenta às discussões promovidas pelo grupo, intervindo em alguns momentos. Mônica mostrou-se, também, muito participativa, e contribuiu muitas vezes durante as discussões em grupo. Nany participou das discussões, e era a única integrante da equipe que já havia desenvolvido tarefas de modelagem. Durante o primeiro bimestre do ano letivo, Nany foi aluna do professor Tito, porém, na turma da noite, onde o professor já havia desenvolvido ambientes de aprendizagem da mesma natureza. Durante o desenvolvimento da modelagem, Nany buscava sempre trazer informações do seu cotidiano, já que a aluna fora catadora de latinhas, tendo, assim, uma relação estreita com a problemática da tarefa.

Stefany tinha um perfil de liderança, revelando, muitas vezes, domínio sobre as decisões da equipe em relação à tarefa. Teti chegou atrasado à sala de

\footnotetext{
${ }^{7}$ Neste trabalho, apesar de reconhecermos as especificidades da EJA, não desenvolvemos uma discussão sobre a modalidade, a fim de não nos desvincularmos do foco do artigo. A EJA é tomada, aqui, apenas como contexto para coleta de dados, não como parte do problema de pesquisa.

${ }^{8}$ Pseudônimo escolhido pelo professor.

${ }^{9}$ Projeto certificado como atividade de extensão da UEFS, Resolução CONSEPE/UEFS 120/2007, coordenado pelo Prof. Dr. Jonei Cerqueira Barbosa e pela Prof ${ }^{a}$. Andréia Maria Pereira de Oliveira. ${ }^{10}$ Pseudônimos adotados pelos alunos.
} 
aula, aderindo, assim, à atividade que já estava em andamento, porém buscou participar ativamente das discussões com os outros integrantes da equipe.

\section{Metodologia}

A escolha metodológica do presente estudo tem como base uma abordagem qualitativa, pois se pretende compreender a regulação do discurso do professor sobre a produção discursiva dos alunos. Segundo Bogdan e Biklen (1994), a palavra qualitativa enfatiza processos e os significados que não são analisados em termos de frequência, quantidade ou volume. Na pesquisa qualitativa, a ênfase está na investigação de como uma experiência social é produzida e adquire significado.

Para dar conta do propósito da pesquisa, o procedimento de coleta de dados adotado foi a observação de um grupo composto por cinco alunos ao desenvolverem um projeto de modelagem em sua sala de aula. $\mathrm{O}$ critério de escolha do grupo foi a maior heterogeneidade dentre as outras equipes formadas. Os alunos são aqueles apresentados na seção anterior. As observações das discussões do grupo em sala de aula foram consideradas parte principal da coleta de dados.

A escolha pela observação deu-se pelo fato de que possibilita a compreensão dos discursos produzidos em sala de aula, permitindo, assim, atender ao objetivo deste estudo. A partir da observação, o pesquisador passa a acompanhar as experiências dos participantes da pesquisa, permitindo coletar impressões (ADLER; ADLER, 1994) da sala de aula em que foi desenvolvido o ambiente de modelagem, buscando compreender o significado que dão às suas próprias ações e à realidade que os rodeia.

Ao acompanhar o grupo de alunos, quando desenvolviam as tarefas propostas pelo professor no ambiente de modelagem, observamos que alguns discursos produzidos pelos alunos precisavam ser melhor compreendidos, a fim de subsidiar nossa análise. Por esse motivo, optamos por elaborar uma entrevista semi-estruturada na tentativa de compreender as ações dos estudantes. Foi organizado um roteiro para ser seguido durante a entrevista. No modelo de entrevista escolhido, poderíamos alterar a ordem dos pontos e, inclusive, formular questões não previstas inicialmente (FONTANA; FREY, 1994). Com a entrevista, pretendíamos explorar trechos dos dados vindos da observação que foram considerados importantes para o propósito do estudo. A observação foi registrada com a câmera de vídeo e as entrevistas com um gravador de voz. 
Para analisar os dados, tomamos inspiração nos procedimentos analíticos de análise de dados da grounded theory (CHARMAZ, 2006). Devemos sublinhar que não compartilhamos de seus pressupostos filosóficos, mas apenas nos apropriamos dos seus insights para procedimentos de análise de dados. Consistiu na leitura, linha por linha, descrevendo e criando três categorias mais gerais a partir desses dados, as quais serão, cada uma, ilustradas com episódios neste artigo.

Bernstein $(1990,2000)$ sustenta que os dados empíricos e a teoria devem ter uma relação dialética. A metodologia de investigação que guiou nossa análise de dados rejeita que a mesma aconteça sem uma base teórica que lhe esteja subjacente, assim como a utilização de uma teoria que não permita sua transformação com base nos dados empíricos. Entendimento que se condensa na noção de linguagens de descrição pelo teórico. Nossa postura, na condução do estudo, foi guiada por esta compreensão.

\section{Apresentação dos dados}

Os recortes dos dados apresentados nesta seção referem-se aos discursos dos alunos e do professor Tito durante o desenvolvimento do ambiente de modelagem, e nas entrevistas feitas com os alunos do grupo observado.

Os dados apresentados foram organizados e transcritos seguindo algumas regras baseadas no estudo de Silva (2002) e inspiradas no trabalho de Sepúlveda (2010): os discursos foram enumerados de (1) a (107) para facilitar seu processo de localização; o símbolo (/) foi utilizado para indicar pausa nos discursos, enquanto o símbolo [...] indica pausa com hesitação; as informações trazidas entre colchetes são explicações dos discursos orais ou gestos produzidos pelos alunos e o professor no ambiente de modelagem; e a expressão aluno(a) $x$ foi utilizada para fazer referência aos alunos que não fazem parte do grupo que foi observado.

Sendo assim, a fim de promover uma compreensão geral de como foi desenvolvido o ambiente de Modelagem na sala de aula do professor Tito, nós o apresentamos a seguir, de forma breve, antes de nos dirigirmos propriamente às categorias e episódios. 


\subsection{A Reciclagem de latinhas de alumínio}

O professor iniciou a aula, entregando aos alunos uma tarefa contendo um texto informativo com o título reciclagem de latinhas de alumínio e três situações-problema, como podemos observar na figura abaixo.

\section{Reciclagem de latinhas de alumínio}

A lata de aluminio é o material reciclável mais valioso. Além de reduzir o lixo que vai para os aterros a reciclagem desse material proporciona significativo ganho energético.

Assim, a reciclagem de latas de alumínio vazias é

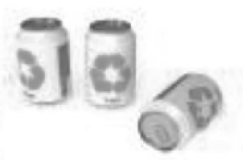
muito importante do ponto de vista da proteção ao meio ambiente e na preservaçào dos recursos naturais e energéticos. Para 1 tonelada de alumínio reciclado deixam de se extrair 5 toneladas de minério (bauxita) e se para produzir essa mesma 1 tonelada é necessário um gasto de $15,000 \mathrm{kwh}$ de energia, se reciclada apenas serão gastos $750 \mathrm{kwh}$ uma economia de $95 \%$. Em termos práticos, isto significa que uma única latinha reciclada economiza energia suficiente para manter uma TV ligada durante 3 horas!

A reciclagem evita a extração da bauxita, o mineral beneficiado para a fabricação da alumina, que é transformada em liga de aluminio. Cada tonelada do metal exige cinco de minério. A lata de alumínio é usada basicamente como embalagem de bebidas. 0 preço pago por uma tonelada de latinhas é, em média, de RS 3.500 - o quilo de latinhas antes da reciclagem equivale a 75 latinhas, essas 75 após o processo de reciclagem produz 62 novas latinhas recicladas.

Informaçōes retiradas dos sites: htto://wnwwnortaldonontal.com/latahthm e http://wrwwsucatas com/curiosidades shtml e na reportagem exibida em

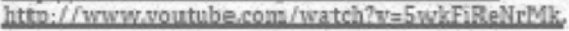

Refletindo sobre o assunto:

1. Como podemos encontrar a quantidade de latinhas que podem ser produzidas com o máximo de processos de reciclagem possível com $1 \mathrm{~kg}$ de latas? E qual o custo benefício para os catadores de latinhas?

2. Qual o impacto desse processo de reciclagem para a preservaçăo do meio ambiente?

3. Do seu ponto de wista, quais fatores fazem com quê $96 \%$ das latinhas produzidas sejam recicladas encuanto a reciclagem de outros materiais como plásticos, papel, vidro etc, nẩo atingem $50 \%$ ?

Figura 1 - Tarefa distribuída por Tito aos alunos.

Em seguida, para dar início à discussão sobre a reciclagem de latinhas, Tito relembrou aos alunos sobre a reciclagem, que foi um dos temas discutidos na gincana realizada anteriormente na escola. Após a discussão, o professor 
apresentou um vídeo com uma reportagem sobre a reciclagem de latinhas de alumínio, procurando saber dos estudantes quais informações do vídeo eles consideraram mais importantes.

O professor solicitou que um dos alunos fizesse a leitura do texto, entregue no início da aula, em voz alta. Logo depois, solicitou que os alunos se organizassem em grupos e utilizassem as informações contidas na tarefa entregue por ele, para que desenvolvessem os problemas propostos. Além disso, destacou que haveria um tempo para a resolução dos problemas e que seria necessária uma apresentação dos resultados finais.

Após a apresentação da tarefa e discussão inicial sobre o tema pelo professor, observamos três categorias, que refletem manifestações da regulação discursiva do professor sobre os alunos, as quais ilustramos com episódios nomeados por nós: regulando os procedimentos de desenvolvimento das situações-problema; silenciando as informações do dia-a-dia; e silenciando os procedimentos matemáticos. Na formação dos episódios, os recortes nem sempre foram apresentados na sequência em que ocorreram na sala de aula observada, mas, organizados de acordo com sua relação com o foco deste estudo.

\subsection{Regulando os procedimentos de desenvolvimento das situações- problema}

Como já apresentado anteriormente, após a discussão da reportagem em vídeo, o professor solicitou a uma aluna x que fizesse a leitura do texto contido na tarefa (Figura 1) em voz alta, e apresentou o que esperava dos alunos no desenvolvimento do ambiente de modelagem.

(1) Tito: Agora eu vou pedir para a aluna x (/) ela ler um texto que complementa um pouco o que foi passado no vídeo (/) para a gente a partir daí poder fazer uma atividade em sala de aula.

A aluna $x$ fez uma leitura em voz alta do texto sobre a reciclagem de latinhas. Em seguida, Tito apresentou algumas considerações sobre as informações lidas.

(2) Tito: E aí também fala que de 75 unidades de latinha (/) até eu achava que fazia 75 latas (/) mas não (/) pelo contrário (/) só dá para fazer 62 de 75 e assim sucessivamente. Aí essas informações foram tiradas tanto do vídeo (/) quanto desse site que está aí embaixo [referindo-se às informações 
contidas na tarefa apresentada na Figura 1] (/) dois sites não é? Aí agora eu queria lançar uma proposta para vocês fazerem em grupo $(/)$ e tentar me responder estes três questionamentos que estão aí embaixo ... Para que vocês possam desenvolver essa atividade, vocês vão ter um tempo para fazer (/) e depois eu vou querer que vocês apresentem aqui na frente o resultado que vocês acharam para a gente poder discutir esses resultados. Vamos lá?

Tito, em seus discursos, apresentou indícios do como esperava que os alunos desenvolvessem e explorassem as situações-problema propostas. No discurso (1) podemos identificar que o professor enfatizou as informações que os alunos deveriam utilizar, legitimando os dados contidos no texto da tarefa e no vídeo. Além disso, Tito indicou em (2) a organização dos alunos, no caso, em grupos, e a necessidade de socializar e discutir os resultados finais.

Após se organizarem em grupos a pedido do professor, os alunos iniciaram uma discussão acerca das situações-problema propostas, como podemos observar abaixo:

(3) Stefany: A partir das informações no texto [...] um quilo [...]. [Olhando para a folha entregue por Tito]. (...)

(4) Stefany: Isso a gente já falou (/) $\mathrm{R} \$ 3,50$ por quilo de lata.

(5) Nany: Não (/) ele quer saber [...]

(6) Stefany: Ó (/) ele está falando aqui (/) a partir das informações encontradas no texto (/) como podemos encontrar a quantidade de latinhas a serem produzidas. [Apontando para a tarefa entregue pelo professor].

(7) Nany: Ele quer saber a partir da reciclagem.

(8) Stefany: O processo de reciclagem por quilo.

(9) Nany: Então essa [...]

(10) Mônica: Um quilograma.

(11) Nany: Não é isso que ele quer? Que depois da reciclagem, quantas consegue?

(12) Stefany: Ah! 62.

(13) Nany: Isso.

(14) Alice: E 75? São 75?

(15) Stefany: Olha (/) 75 (/) cada 75 unidades você produz 62 latinhas. Entendeu Alice?

(16) Nany: Aí (/) manda ele vir para explicar a gente. Eu acho que ele quer dizer é que [...]

(17) Stefany: Quantas vezes [...] de 62 [...] Aí a gente vai diminuir mais quanto? De 75 [...] 
(18) Alice: No caso aí é 13 (/) de 75 para 62 [...]

(19) Stefany: 13 (/) de 62 para 75 vai diminuir de $13 \mathrm{em} 13$

(/) não é? [Fazendo os cálculos no caderno.].

(20) Mônica: Tito! [Chamando o professor.]

(21) Stefany: Então uma vez [...]. [Fazendo o cálculo de 62 menos 13.].

(22) Nany: Professor!

Nos discursos elencados, as alunas buscaram seguir os dados trazidos na tarefa, que pareciam estar associados à produção do discurso esperado pelo professor, já que ele, inicialmente, havia destacado a importância dessas informações no desenvolvimento das situações-problema, legitimando o uso das mesmas.

Assim, os alunos utilizaram, muitas vezes, o pronome ele, se referindo ao professor, para argumentarem suas ideias. O fato é identificável nos discursos de Nany em (5), (7) e (11), ou também no discurso (6) de Stefany. Podemos entender que os alunos associaram o discurso escrito na tarefa ao discurso do professor.

Ainda, no recorte citado, observa-se que o grupo buscou compreender como deveria ser abordada a situação-problema com base no discurso elaborado pelo professor, já que, quando Alice em (14) questionou sobre a perda de latinhas no processo de reciclagem, Stefany argumentou em (15) que a cada 75 unidades seriam produzidas 62 latas. Este argumento foi apresentado na tarefa e destacado por Tito em (2), o que pode ter levado Stefany a considerá-lo relevante no desenvolvimento do problema.

Ao apresentarem dúvidas sobre o que estava sendo solicitado na primeira situação-problema, os alunos solicitaram a presença do professor.

(23) Nany: Vamos dizer assim (/) desse 75 a gente usou 13 (/) aí agora nesse 49 a gente tem que usar menos que treze? [Nany questiona ao professor se a redução será fixa para os processos de reciclagem.]

(24) Tito: Não (/) aqui a diferença é treze (/) depois de novo 13 (...) aí você já colocou a diferença fixa para [...] e sobrou 10 latinhas. [Aqui o professor sugere que a redução nos processos de reciclagem sejam fixas, mas que com esta redução há uma sobra de 10 latas.]

(25) Nany: Sobrou 10 latinhas. (...)

(26) Stefany: (...)como podemos encontrar a quantidade de latinhas a serem produzidas com o máximo de processo de 
reciclagem possível com um quilograma de latas? Quer dizer (/) com 75 o máximo de reciclagem de latas possível [...] reciclar (/) reciclar (/) quando é que vai [...] (27)Tito: São cinco reciclagens completas.

(28) Stefany: São cinco reciclagens completas e ainda sobraram dez latinhas.

(29) Tito: E essas dez latinhas eu não posso reciclar mais?

(30) Stefany: É isso que a gente queria reciclar, mas [...]

(31) Nany: Nem que seja uma.

(32) Stefany: Uma. [A aluna sugere um novo valor para a quantidade de latinhas restantes após os processos de reciclagem]

(33) Nany: Nem que seja uma ou duas latinhas serve.

(34) Tito: É (/) mas tente ver isso aí.

(35) Stefany: Seis (/) pode ser seis.

(36) Nany: Vamos ver aí.

(37) Stefany: Porque seis a gente pode reciclar (/) não significa que vai ficar um (/) mas fica alguma coisa.

(38) Nany: É (/) mas vai reciclar.

O discurso de Nany em (23) indica que a aluna levantou a possibilidade da perda de latinhas não ser fixa durante o processo de reciclagem, porém, a intervenção do professor fez os alunos trabalharem com um valor de perda constante. Observamos, assim, que os alunos passaram a lidar com a hipótese apresentada por Tito, oferecendo mais estrutura à situação.

Tito, ao intervir na discussão sobre a questão presente na primeira situação-problema, apresentou evidências de que as 10 latinhas finais que os alunos haviam encontrado ainda deveriam ser recicladas, como podemos observar no discurso (29): e essas dez latinhas eu não posso reciclar mais? As alunas demonstraram interesse em buscar atender à observação feita pelo professor. No discurso abaixo, extraído da apresentação final, observamos que Stefany produziu seu discurso com base nas intervenções discursivas do professor durante o desenvolvimento da situação-problema.

(39) Stefany: A gente fez o seguinte cálculo (/) como aqui no texto diz que 75 unidades de latinhas (/) com (/) 75 latinhas recicladas (/) 62 latinhas são feitas (/) a gente fez o seguinte cálculo (/) 75 menos 62 deu 13 (/) aí no caso esse 13 é o que a gente foi diminuindo de cada reciclagem de latinha ... aqui foi um processo (/) segundo (/) terceiro (/) quarto e o quinto (...) só que sobraram 10 latinhas (/) então essas 10 latinhas 
ainda podem ser reaproveitadas (/) então no caso ficou seis processos de reciclagem.

$\mathrm{O}$ fato de Tito ter dado indícios da necessidade de reciclar as 10 latinhas que sobraram nas suposições realizadas pelo grupo fez com que os alunos acrescentassem um processo de reciclagem. Isso foi observado na apresentação dos resultados finais, no discurso acima, os quais foram socializados por Stefany.

Após a discussão da primeira situação-problema, o professor se aproximou da equipe e discutiu acerca das dúvidas dos alunos sobre as questões. (40) Nany: Qual é o custo beneficiado para os catadores de latinhas? O senhor quer saber como? Com base aqui no texto? (...)

(41) Tito: Preste atenção (/) eu tenho 75 (/) certo? Das 75 eu vou produzir 62 que você falou (/) não é isso? Reciclar (/) depois 49 (/) depois 36 (/) depois 23 (/) depois 10 (/) Qual o total de latas que eu vou poder fazer a partir de 75 latinhas? (42) Stefany: É isso aí que a gente estava em dúvida, porque a gente estava querendo saber se estava perguntando por quilo ou por cada etapa dessa daqui.

(43) Tito: Mas eu quero saber qual o custo-benefício através do máximo de processo de reciclagem. [O intuito do professor foi explicar que após todos os processos possíveis de reciclagem a partir de 75 latas de alumínio, eram produzidas uma quantidade total de latas, a qual ele desejava saber o valor]

(44) Stefany: Ah (/) eu não tinha entendido que era o máximo de processo aqui não.

No recorte de dados acima, observamos que a equipe buscou compreender o problema acerca do custo-benefício para os catadores de latinha. E Tito em (41) apresentou quais procedimentos deveriam ser realizados para o desenvolvimento da situação-problema. Desse modo, o professor indicou que as alunas deveriam encontrar a quantidade total de latinhas produzidas após a realização de todos os processos de reciclagem.

O discurso abaixo foi extraído da apresentação final. Nele podemos identificar que as alunas buscaram produzir as sugestões dadas pelo professor no recorte anterior.

(45) Stefany: Aí depois (/) nós somamos tudo para saber quantas latinhas no caso foram feitas nesse processo todinho de reciclagem. 
No discurso acima, novamente observa-se que o grupo calculou a quantidade de latinhas a ser produzidas, encontrando a quantidade total de latinhas produzidas após todos os processos de reciclagem.

Assim, o professor indicou os procedimentos a ser realizados para a resolução da situação-problema sobre o custo-benefício para os catadores de latinhas, apresentando que deveria ser encontrada uma quantidade total, e foi o que a equipe fez como vimos em (45).

Este episódio sugere que o professor enquadrou o modo como deveria ser a abordagem das situações-problema, por meio da indicação de quais procedimentos poderiam ser utilizados no desenvolvimento do ambiente de aprendizagem. No episódio apresentado a seguir, trazemos alguns recortes de dados nos quais podemos observar que Tito, por meio de suas produções discursivas, silenciou a escolha das informações trazidas do dia-a-dia pelos alunos no processo de resolução das situações-problema.

\subsection{Silenciando as informações do dia-a-dia}

Nos recortes que serão apresentados inicialmente, foi identificada a discussão dos alunos sobre a escolha dos dados que seriam utilizados na resolução dos problemas propostos pelo professor, como observamos abaixo:

(46) Stefany: Se for por esse um quilo que a pessoa for reciclar (/) vai ser R\$3,50 não é? Mas se a pessoa for reaproveitar essas novas latinhas que reciclaram (/) eu não sei se é assim entenderam? É de acordo com cada reciclagem. (47) Nany: E uma coisa (/) que a latinha é variada o valor (/) tem tempo que o custo está maior (/) e tem tempo que o custo está menor.

(48) Mônica: Eé?

(49) Nany: É (/) e na latinha de ferro (/) ela de ferro um quilo é cinco centavos.

(50) Mônica: E porque ela custa [...] essa custa $\mathrm{R} \$ 3,50$ ?

(51) Nany: Tem festa que pode subir para $\mathrm{R} \$ 0,10(/)$ Agora essa daqui (/) reciclagem que demora mais (/) de alumínio (/) ela está de [...] R \$2,50 (/) aí em festa ela aumenta.

(52) Alice: Mas vê aí quanto é que tem no papel (/) depois resolve [Referindo-se às informações contidas na tarefa entregue pelo professor].

(53) Stefany: Três e [...] três mil e quinhentos dividido pela tonelada de alumínio (/) dá $\mathrm{R} \$ 3,50$. Três mil e quinhentos dividido por mil (/) dá $\mathrm{R} \$ 3,50$. 
Apesar dos integrantes do grupo terem mostrado interesse nas informações trazidas por Nany, Alice mostra preocupação em seguir as informações contidas na tarefa entregue por Tito para iniciar o processo de resolução da situação-problema, como vimos em (52). Isso pode ter sido decorrente da indicação do professor em utilizar os dados da tarefa entregue por ele, como vimos no episódio anterior.

Apesar de Alice ter questionado a legitimidade das informações trazidas por Nany, observamos, nos discursos abaixo, que Nany insistiu para que o grupo utilizasse a variação de valores da latinha para o desenvolvimento do problema.

(54) Stefany: $\mathrm{R} \$ 3,50$ (/) não tem outro.

(55) Nany: Não (/) mas ele falou e eu disse [...]

(56) Stefany: Por quilo.

(57) Nany: Porque é variada às vezes (/) depende tem [...] agora mesmo não deve está de $\mathrm{R} \$ 3,50$ (/) no mínimo deve está de $\mathrm{R} \$ 2,50(/) \mathrm{R} \$ 2,00$.

(58) Stefany: Mas ele está dizendo a partir daqui [A aluna aponta para a tarefa entregue].

(59) Nany: Ah.

No discurso (54), Stefany defendeu o uso apenas do valor R \$ 3,50 para o quilo de latas de alumínio, uma vez que nas informações contidas na tarefa encontrou-se apenas um preço, $\mathrm{R} \$ 3,50$. Em (55), Nany tentou argumentar em seu favor, utilizando a legitimidade do discurso de Tito, como em - "mas ele falou". Todavia, Stefany insistiu em seguir as informações fornecidas pelo professor, ou seja, os dados contidos na tarefa.

Apesar de em (59) Nany parecer ter se conformado com o argumento de Stefany, ela insistiu na utilização de valores menores para as latinhas.

(60) Stefany: Ó (/) presta atenção Teti (/) essa pergunta qual o custo benefício para os catadores de latinha (/) ele não está falando só um catador (/) ele está falando os catadores.

(61) Nany: Eu acho que é com base nos cálculos que a gente fez aqui (/) ele quer saber no mínimo (/) não é isso? No mínimo de quanto? Quanto é o lucro que os catadores têm (/) não? É (/) eu acho que deve ser isso (/) com base no que a gente fez $(/)$ entendeu?

(62) Stefany: Nany (/) só tem uma resposta para isso (/) $\mathrm{R} \$ 3,50$.

(63) Nany: Ele quer saber por esse aqui mesmo? Por aqui?

(64) Alice: Tem que ser com base no texto.

(65) Teti:É. 
Nany em (61) argumentou sobre o enunciado do problema, apresentando que deveria ser encontrado o custo mínimo para as latinhas. Stefany, insatisfeita com o argumento de Nany, insistiu mais uma vez em (62) que R \$ 3,50 era o único valor legítimo para ser considerado na resolução. Alice e Teti em (64) e (65) também reafirmaram a necessidade de se basearem nas informações presentes na tarefa. Utilizar os dados da tarefa, pareceu, para os alunos, ser uma forma de produzir o discurso esperado pelo professor.

Nany explicou o seu interesse em utilizar outros valores para o quilo da lata de alumínio, como vemos abaixo no discurso extraído da entrevista:

(66) Nany: É porque eu sugeri fazer pelo meu valor (/) porque antigamente minha mãe há uns dois meses atrás (/) ela era catadora de latinhas (/) toda vez que ela ia catar latinha (/) eu ia com ela (/) aí por isso eu já sabia mais a base de quanto era $(/)$ entendeu? (ENTREVISTA, 10/2010).

A insistência de Nany em utilizar a variação de preços da latinha, pode ser entendida pelo fato dela ter considerado legítimo utilizar valores trazidos de sua experiência cotidiana acerca das latinhas de alumínio. Apesar das situaçõesproblema estarem relacionadas ao cotidiano de Nany, o qual exerceu forte influência sobre os argumentos produzidos pela aluna durante as discussões com o grupo, ela teve interesse em produzir um discurso que fosse legítimo para o professor, como podemos observar abaixo:

(67) Nany: Õ professor, faça o favor (/) Meu juízo está aqui pegando fogo. (...)

(68) Nany: Ô professor (/) mas o valor não é fixo (/) porque a latinha (/) tem lata que em tempo de festa é $\mathrm{R} \$ 3,50$ (/) quando não é no período de festa ela vai para $R \$ 2,00$ (/) vai para $\mathrm{R} \$ 2,50$.

(69)Stefany: Mas esse problema é baseado(/) está baseado só no que está escrito aqui.

(70) Tito: É.

(71) Mônica: A gente tem que se basear nesse papel.

(72)Stefany: Baseado aqui dá $\mathrm{R} \$ 3,50$ (/) entendeu?

(73)Tito: Porque se você for ficar baseando em 2 e 3 (/) você não vai conseguir achar o valor.

(74)Teti: Baseado num valor só.

Nany preocupou-se em atender as expectativas do professor, como já visto nos discursos (63) e (67). Além disso, Nany solicitou a presença de Tito 
junto à equipe para reconhecer se era legítimo considerar os dados trazidos de sua experiência com a venda de latas de alumínio.

Em (70), Tito concordou com o argumento de Stefany em utilizar as informações apresentadas na tarefa. Já em (73), o professor evidenciou os dados que poderiam ser utilizados na resolução das situações-problemas. Além disso, enfatizou que a utilização dos outros valores, propostos por Nany, não levaria a um resultado final para o problema, reafirmando as opiniões dos alunos sobre o que consideravam legítimo para o desenvolvimento do ambiente, como em (69), (71) e (74).

Após a intervenção do professor, os discursos de Nany com relação aos dados trazidos de suas experiências pessoais com o tema foram silenciados. Durante a aula, a aluna não propôs mais a utilização dos valores apresentados por ela inicialmente, desenvolvendo os cálculos a partir dos dados sugeridos pelo professor.

Durante as entrevistas com os alunos do grupo observado, eles foram questionados sobre a preferência em utilizar os dados contidos na tarefa entregue por Tito, em detrimento dos valores fornecidos por Nany.

(75) Stefany: Porque é melhor se basear naquilo que está escrito (/) não é? Ali já é uma coisa fixa (/) não é? ... Porque já é um dado específico que ele deu ali (/) entendeu? (ENTREVISTA, 10/2010).

(76) Mônica: A gente optou mais pelo o que o professor deu (/) porque a gente ia acertar mais o assunto que ele deu (/) porque aquilo ali valia ponto (/) entendeu? Então a gente optou por aquele ali para a gente acertar mais. (ENTREVISTA, 10/2010).

(77) Alice: Porque ele já sabia como é mais ou menos a atividade. (ENTREVISTA, 10/2010).

(78) Teti: tem que achar o resultado exatamente como está no papel que ele deu ali (/) ... Porque já estava com o número (/) não é? ... Ele ia avaliar pelo que estava escrito ali (...) também ia achar errado se não estivesse batendo os números (/)... Porque ele que deu os dados. (ENTREVISTA, 10/2010).

Em (76), por exemplo, Mônica preocupou-se com a maneira como Tito iria avaliar a abordagem das questões, e que caso utilizassem outros dados poderiam obter resultados diferentes do esperado pelo professor, como podemos também observar em (78). 
No discurso (77) de Alice, podemos compreender que houve um reconhecimento do professor como o sujeito que possui o domínio sobre o que pode ou não ser feito em sala de aula, no caso, no desenvolvimento do ambiente de modelagem.

Até aqui, observou-se que as informações do dia-a-dia movidas das práticas cotidianas de Nany para a sala de aula foram silenciadas. Primeiramente, houve uma tentativa dos alunos de silenciar o discurso de Nany, mediante o argumento de que deveriam ser utilizadas as informações contidas na tarefa entregue pelo professor. Contudo, podemos dizer que é o discurso do professor que silencia a escolha de Nany em utilizar dados do seu cotidiano, uma vez que, para a aluna, o discurso de Tito era legítimo no desenvolvimento do ambiente de aprendizagem.

Tito, além de ter considerado legítimos os discursos produzidos pelos outros integrantes da equipe, enfatizou que o uso dos dados propostos por Nany implicaria em não produzir uma solução final esperada para a situação-problema. A seguir, apresentamos as interações discursivas dos alunos e professor na escolha de uma operação matemática a ser utilizada na resolução das situaçõesproblema.

\subsection{Silenciando os procedimentos matemáticos}

Apresentamos, agora, os discursos produzidos no processo de escolha da operação matemática pelos alunos e nos cálculos realizados para a obtenção dos resultados finais a ser socializados com a turma.

(79) Tito: Porque é o seguinte (/) aí está dizendo o seguinte (/) que 1 quilo de lata dá 75 latas (/) e que depois se eu pegar essas 75 e reciclar vai dá 62 (/) então na primeira questão eu estou querendo o seguinte (/) qual o máximo de processos possíveis de reciclagem? Se eu tenho 75 eu vou reduzir para 62 (/) não é isso? Se eu pegar 62 e reciclar de novo vai dar 62 ?

(80) Stefany, Nany, Mônica: Não!

(81) Tito: Vai dar menos (/) Então eu quero saber o seguinte (/) qual é [...]quantas vezes eu posso [...] então vai ter um momento que vai zerar (/) não vai? [O professor tentou explicar quantas latinhas seriam produzidas após o máximo de processos de reciclagem].

(82) Teti: Vai.

(83) Tito: Porque de 62 vai diminuir (/) depois vai diminuindo 
(/) diminuindo até chegar a zero (/) Qual o máximo possível de reciclagem que posso fazer com 62 [...] com 75 (/) Então quantas latinhas a partir de 75 eu posso produzir?

(84) Mônica: Aí, nesse caso, vai ficar 62 mais (/) cinquenta e [...] deu quanto Stefany? [A aluna sugeriu que fosse feita a soma dos números de latinhas encontradas ao final de cada processo de reciclagem].

(85) Tito: Porque você somou? [Questionando o discurso enunciado por Mônica].

(86) Mônica: Porque tem que somar.

(87) Tito: Não (/) porque você somou?

(88) Stefany: É subtrair.

O recorte acima foi marcado pelo discurso de Tito durante todo o diálogo, no qual ele foi dirigindo a discussão para aquilo que ele esperava que fosse produzido pelos alunos na resolução da situação-problema. As intervenções de Tito levaram Mônica a concluir que deveria ser feita a soma das quantidades de latinhas recicladas após o máximo de processos de reciclagens, como vemos em (84). Ao ser questionada por Tito em (85), Mônica não argumenta sua escolha.

A insistência de Tito em questionar o porquê da escolha pela soma, não aceitando a resposta de Mônica em (87), levou Stefany a pronunciar sua preferência pela subtração como operação mais apropriada. A seguir, o professor questiona a escolha de Stefany,

(89) Tito: E porque tem que subtrair?

(90) Stefany: Porque ó (/) se de 75 se perde 13 [...]

(91) Tito: Não (/) mas eu quero saber o seguinte (/) eu quero saber o máximo possível de latinhas (/) Mônica está certa (/) vai ter que somar (/) mas porque vai ter que somar?

O professor questionou em (89) a escolha de Stefany pela subtração. A aluna argumentou que no processo de reciclagem ocorre a perda de latinhas, e que, por esse motivo, optou pela subtração. Todavia, Tito enfatizou a legitimidade do discurso de Mônica, afirmando que a operação a ser utilizada deveria ser a soma.

Nos discursos abaixo, também Teti passou a argumentar positivamente a utilização da soma na resolução da situação-problema.

(92) Stefany: Não é de somar é de subtrair.

(93) Teti: Não (/) mas vai ter que somar (...) não é professor?

(94) Tito: É. 
(95) Teti: Vai estar produzindo latas [Argumentando a favor do uso da soma]

(96) Tito: Qual é o total Stefany de latas que eu posso produzir?

(97) Mônica: 75 (/) não é? 75 dá 62 (/) então vai fazer 62 mais [...] Cadê o outro?

(98) Stefany: 49.

(99) Mônica: Mais 49

(100) Stefany: Mais $36(/)$ mais $23(/)$ mais 10.

(101) Mônica: É.

(102) Teti: Porque? Por que aqui a gente vai está produzindo lata (/) está produzindo lata.

(103) Mônica: É (/) Porque 75 produziu 62 [...] 62 (/) 62 produziu 49.

(104) Teti: Agora eu entendi (/) Fica olhando (/) [Teti tomou a tarefa das mãos de Stefany]

(105) Stefany: Sim (/) Me dá aí (/) [Stefany toma o papel das mãos de Teti]

(106) Stefany: Mais (/) 11 (/) 17 (...) 180 [Stefany faz os cálculos utilizando a soma]

Teti em (93) argumentou o uso da soma, garantindo, assim, a legitimidade de seu discurso, a partir do discurso de Tito em (94). Em (96), Tito tentou explicar a Stefany o uso da soma na situação-problema, levando a aluna a utilizar a adição em sua resolução, como vimos em (100) e (106). Apesar de Stefany destacar e argumentar sua escolha pela subtração no desenvolvimento da situação-problema, os discursos de Tito levaram a aluna a produzir discursos que legitimavam o uso da soma nos cálculos para encontrar a quantidade total de latas, silenciando a hipótese anterior de Stefany.

No recorte abaixo, referente à apresentação final da equipe, podemos identificar que os alunos buscaram produzir as sugestões dadas pelo professor no recorte anterior.

(107) Stefany: Aí a gente fez a soma de 62 mais 49 (/) mais 36 (/) mais 23 (/) mais 10 que foram as que sobraram (/) no total deu 180 latinhas.

No discurso acima, temos que o grupo calculou a quantidade total de latinhas a ser produzidas, o que levou à soma de todas as latas encontradas após a realização do máximo de processos de reciclagem. Sendo assim, observamos que Tito, por meio de seus discursos, indicou qual operação matemática deveria 
ser utilizada no desenvolvimento da situação-problema.

Os dados apresentados até aqui sugerem que os discursos produzidos por Tito levaram a equipe, em alguns momentos, a desistir de suas escolhas e seguir os procedimentos indicados pelo professor. A seguir, esses dados serão discutidos com o auxílio de conceitos teóricos abordados pelo sociólogo Basil Bernstein, promovendo um diálogo entre os dados empíricos e a teoria, a fim de gerar novas compreensões teóricas, para melhor compreender como os discursos do professor podem regular os discursos dos alunos num ambiente de modelagem.

\section{Discussão dos dados}

Neste estudo, nosso propósito foi analisar como o discurso do professor pode regular as produções discursivas dos alunos em um ambiente de modelagem. Nosso objetivo baseou-se na ideia de regulação proposta por Bernstein (2000), como o uso das regras que permitem reconhecer e produzir a comunicação esperada na relação pedagógica. Assim, ao analisar uma aula de matemática, na qual o professor desenvolveu um ambiente de modelagem, foi possível observar a maneira como o professor interveio nas discussões dos alunos nesse ambiente de aprendizagem, e como isso pode ter regulado a produção discursiva dos estudantes.

Para tanto, os dados foram organizados em três categorias, ilustradas através de episódios, nas quais observamos que houve a tentativa dos alunos de produzir o discurso que era esperado pelo professor. Desse modo, em termos do modelo teórico de Bernstein (2000), compreendemos que o discurso do professor parecia sinalizar para os estudantes o que seria legítimo que eles produzissem na prática pedagógica.

Durante o desenvolvimento do ambiente de modelagem, os alunos tentaram compreender e abordar a situação-problema, por meio do reconhecimento do que o professor considerava como legítimo. Assim sendo, a tarefa entregue pelo professor no início da aula e os discursos produzidos por Tito se constituíram como indicações para o reconhecimento das informações legítimas para aquela prática.

Segundo Bernstein (2000), para que seja produzido o discurso legítimo é necessário ter o domínio das regras de reconhecimento, que, como já apresentado anteriormente, permitem distinguir entre os discursos que são considerados legítimos ou não em uma determinada prática. Desse modo, quando os alunos não tinham o domínio sobre as regras de reconhecimento (BERNSTEIN, 2000) 
para um ambiente de modelagem matemática, eles solicitavam a presença do professor para que lhes oferecesse pistas sobre a legitimidade dos discursos produzidos por eles para o desenvolvimento da tarefa.

A aluna Nany, por exemplo, havia vivenciado práticas de modelagem com o professor Tito durante a primeira unidade, diferentemente dos outros alunos. Além disso, já tinha contato, em seu cotidiano, com o tema abordado em sala de aula: a reciclagem de latinhas de alumínio. Desse modo, Nany tentou enfraquecer o controle discursivo, pois ela buscou discutir aspectos que não haviam ainda sido trazidos pelos seus colegas e professor. Além disso, tentou enfraquecer o controle sobre o modo de produzir um discurso naquele contexto, pois queria propor a mudança na escolha dos dados propostos pelo professor no ambiente de modelagem.

Porém, Nany reconheceu a legitimidade do discurso do professor no desenvolvimento das tarefas em sala de aula, solicitando sua opinião, para que pudesse distinguir quais discursos Tito considerava legítimos. O professor, após suas intervenções, acabou por silenciar os discursos de Nany, considerando-os ilegítimos, os quais faziam referência ao valor apresentado por Nany para a lata de alumínio, informação movida por ela de seu dia-a-dia.

Através de suas intervenções discursivas, Tito tentava mostrar quais dados seriam adequados para aquele contexto, e como esses poderiam ser utilizados na resolução da situação-problema. Tal discussão nos leva a enfatizar a natureza reguladora do discurso do professor sobre a produção discursiva dos alunos ao participarem de um ambiente de modelagem.

Assim, as sugestões propostas por Nany foram consideradas inadequadas por Tito, o qual enfatizou que a escolha de outros valores não levaria a um resultado final a ser legitimado. Nany reconheceu as especificidades do contexto em que estava inserida e deixou de propor outros valores para as latinhas de alumínio, aproximando-se das regras de reconhecimento e realização (BERNSTEIN, 1990) feitas mais visíveis pelo professor, resultado que corrobora aqueles apontados por Levinson et al. (2006). Os autores destacam que algumas ações dos alunos podem ser consideradas ilegítimas pelo professor, o que pode levar a um silenciamento das produções discursivas dos estudantes.

Como se pode depreender da análise de dados apresentada neste artigo, os outros integrantes do grupo optaram por utilizar apenas as informações entregues pelo professor na tarefa. Fato que, provavelmente, ocorreu porque essas informações representavam um discurso legítimo para eles. Assim, os alunos resistiram em aceitar as propostas de Nany, já que o seu discurso fora 
considerado ilegítimo, pelo professor, para o desenvolvimento do ambiente de modelagem.

Na tentativa de globalizar a análise, podemos dizer que os discursos dos alunos foram regulados por dois tipos de discursos produzidos pelo professor: $\mathrm{o}$ discurso procedimental e o discurso silenciador. O discurso procedimental refere-se ao discurso do professor, no qual ele deixa evidentes os procedimentos de abordagem do problema no ambiente de aprendizagem, como: onde as informações podem ser coletadas; quais informações são relevantes para o desenvolvimento das situações-problema; e como podem ser desenvolvidas as situações-problema. Já o discurso silenciador refere-se à invalidação de encaminhamentos propostos pelos alunos, como aqueles em termos de que dados devem ser utilizados, das informações relevantes etc.

Observemos que os discursos, procedimental e silenciador, por exercerem um efeito regulador sobre os alunos podem ser vistos como manifestação de uma pedagogia visível. Segundo Bernstein (1990), tal modalidade é aquela em que o discurso dos agentes são avaliados publicamente em termos de critérios de validade. Nesse caso, há um esforço para comunicar os princípios que regulam a práticas pedagógicas, portanto, em última instância, visibilidade à própria regulação.

Desse modo, a partir dos discursos produzidos por Tito nas intervenções no grupo, houve um reconhecimento e realização pelos alunos do discurso esperado pelo professor. Houve, então, uma aproximação dos alunos sobre as regras que permitem reconhecer e produzir a comunicação esperada na prática pedagógica, hierarquicamente sob o controle do professor.

\section{Conclusões}

A análise e discussão dos dados apresentados neste artigo sugerem a existência de dois discursos regulativos produzidos pelo professor no desenvolvimento do ambiente de modelagem: o discurso procedimental e o discurso silenciador. Tais discursos dão visibilidade sobre as regras para as produções discursivas dos alunos nesse ambiente de aprendizagem, seja no abandono das hipóteses levantadas por eles, ou na escolha dos conteúdos matemáticos ou dados a serem utilizados na resolução das situações-problema.

Assim, os estudos sobre os discursos procedimentais e silenciadores podem contribuir para a formação do professor em modelagem, já que o reconhecimento de tais discursos como reguladores das produções discursivas 
dos alunos pode levar os docentes a analisarem suas práticas pedagógicas.

Portanto, é importante observar a maneira como os professores intervêm no desenvolvimento da modelagem pelos estudantes. Segundo Levinson et al. (2006), os discursos do professor podem regular a prática dos alunos, silenciandoos em alguns momentos, a partir da forma como produzem suas interações discursivas. Observar a importância do discurso do professor na regulação da produção discursiva dos alunos pode ajudar a potencializar o ambiente de modelagem.

Além disso, pode colaborar com as pesquisas em modelagem no que se refere à compreensão dos discursos produzidos por alunos e professor nesse ambiente de aprendizagem, já que são posicionadas lentes sobre as relações hierárquicas presentes em salas de aula e, consequentemente, como elas podem regular as produções discursivas desenvolvidas nesse contexto.

As noções sintetizadas aqui - discursos procedimental e silenciador podem, também, ser empregadas para compreensão da relação pedagógica em outros ambientes de aprendizagem. Entretanto, para atingir essa finalidade, é preciso que outras pesquisas gerem subsídios empíricos para sua melhor elaboração. Ademais, os resultados deste estudo podem ajudar a refinar a teoria de Basil Bernstein, uma vez que apresentam novos conceitos que podem auxiliar na compreensão dos discursos produzidos por professores e estudantes em determinado contexto.

\section{Referências}

ADLER, P. A.; ADLER, P. Observational techniques. In: DENZIN, N. K.; LINCOLN, Y. S. (Eds.). Handbook of qualitative research. Thousand Oaks: Sage, 1994. cap. 23. p. 377-392.

ALMEIDA, L. M. W; DIAS, M. R. Um estudo sobre o uso da Modelagem Matemática como estratégia de ensino e aprendizagem. Bolema, Rio Claro, v. 17, n. 22, p. 19-35, 2004.

ALRØ, H.; SKOVSMOSE, O. O Diálogo e aprendizagem em Educação Matemática. Belo Horizonte: Autêntica, 2006. 158p. (Coleção Tendências em Educação Matemática).

ASSIS, A.; TEIXEIRA, O. P. B. Dinâmica discursiva e o ensino de física: análise de um episódio de ensino envolvendo o uso de um texto alternativo. Ensaio de Pesquisa em Educação em Ciências, Belo Horizonte, v. 9, n. 2, p. 1-17, 2007. 
BARBOSA, J. C. Modelagem na Educação Matemática: contribuições para o debate teórico. In: REUNIÃO ANUAL DAASSOCIAÇÃO NACIONAL DE PÓSGRADUAÇÃO E PESQUISAEM EDUCAÇÃO, 24., 2001, Caxambu. Anais... Caxambu: Associação Nacional de Pós-Graduação e Pesquisa em Educação, 2001. p. 1-14. 1 CRROM

BARBOSA, J. C. Modelagem Matemática na sala de aula. Perspectiva, Erechim, v. 27, n. 98 , p. 65-74, jun. 2003.

BARBOSA, J. C. Mathematical modelling in classroom: a critical and discursive perspective. ZDM - The International Journal on Mathematics Education, Eggenstein, Leopoldshafen. v. 38, n. 3, p. 293-301, June 2006.

BARBOSA, J. C. Teacher-student interactions in mathematical modellig. In: HAINES, C. et al. (Eds.) Mathematical modelling: education, engineering and economics. Chischeter: Horwood Publishing, 2007a. p. 232-240.

BARBOSA, J. C. Sobre a pesquisa em Modelagem Matemática no Brasil. In: CONFERÊNCIA NACIONAL SOBREMODELAGEMNAEDUCAÇÃO MATEMÁTICA, 5., 2007, Ouro Preto. Anais... Ouro Preto: UFOP/UFMG, 2007b. p. 82103.

BARBOSA, J. C. Modelagem e modelos matemáticos na Educação Científica.

Alexandria: Revista de Educação em Ciência e Tecnologia, Florianópolis, v. 2, n. 2, p. 65-85, 2009.

BASSANEZI, R. C. Ensino-aprendizagem com modelagem matemática. 2.ed. São Paulo: Contexto, 2004.392p.

BERNSTEIN, B. Class, codes and control: the structuring of pedagogic discourse. London: Routledge, 1990. v.4.

BERNSTEIN, B. Pedagogy, symbolic control and identify: theory, research, critique. Lanham: Rowman \& Littlefield Publishers, 2000.230 p.

BOGDAN, R C.; BIKLEN, S.K. Investigação Qualitativa em Educação: uma introdução à teoria e aos métodos. Portugal: Porto Editora, 1994. 336p.

BORBA, M. C.; MENEGHETTI, R. C. G.; HERMINI, H. A. Estabelecendo critérios para avaliação do uso de modelagem em sala de aula: estudo de um caso em um curso de Ciências Biológicas In: BORBA, M. C. (Org.). Calculadoras gráficas e educação matemática. Rio de Janeiro: MEM/USU, Ed. Art. Bureau, 1999. p. 95-113. 
CALDEIRA, A.D. Modelagem Matemática e Formação de Professores: O que isto tem a ver com as licenciaturas? In: CONFERÊNCIA NACIONAL SOBRE MODELAGEM MATEMÁTICA E EDUCAÇÃO MATEMÁTICA, 5., 2007, Ouro Preto. Anais... Ouro Preto: UFOP, 2007. p. 69-81. 1 CD-ROM

CHARMAZ, K. Constructing Grounded Theory: a practical guide through qualitative analysis. Thousand Oaks: SAGE Publications, 2006. 208 p.

CHRONAKI, A.; CHRISTIANSEN, I. M. Challenging perspectives on mathematics classroom communication: from representations to contexts, interactions, and politics. In: CHRONAKI, A.; CHRISTIANSEN, I. M. Challenging perspectives on mathematics classroom communication. Greenwich: IAP, 2005. p. 3-31.

FERREIRA D. H. L; WODEWOTZKI M. L. L. Questões ambientais e Modelagem Matemática: uma experiência com alunos do ensino fundamental. In: BARBOSA, J. C.; CALDEIRA, A. D.; ARÁUJO, J. L. (Orgs.). Modelagem Matemática na Educação Matemática Brasileira: pesquisas e práticas educacionais. Recife: SBEM, 2007. p. 115-132.

FONTANA, A.; FREY, J. H. Interviewing: the art of science. In: DENZIN, N. K.; LINCOLN, Y. S. (Eds.). Handbook of qualitative research. Thousand Oaks: Sage, 1994. p. 361-376.

FREIRE, P. Pedagogia do Oprimido. 36. ed. Rio de Janeiro: Paz e Terra, 2003.

FREUND, C. S. Professores, alunos e suas famílias: uma análise da escola a partir de idéias de Basil Bernstein. Olhar de Professor, Ponta Grossa, v. 11, n. 1, p. 43-62, 2008.

\section{JACOBINI, O. R. A Modelagem Matemática como instrumento político na sala de} aula. 2004. 215f. Tese (Doutorado em Educação Matemática) - Instituto de Geociências e Ciências Exatas, Universidade Estadual Paulista, Rio Claro, 2004.

LEIB, D. Teacher intervention versus self-regulated learning? Teaching Mathematics and its Applications, Oxford, v. 24, n. 2-3, p. 75-89, Sep. 2005.

LEVINSON, E. et al. Mathematically and practically- based explanations: individual preferences and sociomathematical norms. International Journal of Science and Mathematical Education, Taiwan, v. 4, n. 2, p. 319-344, July 2006.

MAAB, K. Barriers and opportunities for the integration of modelling in mathematics classes: results of an empirical study. In: BLOMHOJ, M.; BRANDELL, G.; NISS, M. (Eds). Teaching mathematics and applications: the $10^{\text {th }}$ ICME. Conpenhagen, 2005. p. 61-74. 
MAULANA, R. et al. Teacher-student interpersonal behavior in secondary mathematics classes in Indonesia. International Journal of Science and Mathematical Education, Taiwan, v.10, n.1, fev., 2011.

OLIVEIRA, M. L. C. As estratégias adotadas pelos alunos na construção de modelos matemáticos. 2007. 130f. Dissertação (Mestrado em Ensino, Filosofia e História das Ciências) - Instituto de Física, Universidade Estadual de Feira de Santana, Feira de Santana, 2007.

OLIVEIRA, A. M. P. Modelagem Matemática e as tensões nos discursos dos professores. 2010. 200f. Tese (Doutorado em Ensino, Filosofia e História das Ciências) - Instituto de Física, Universidade Federal da Bahia, Salvador, 2010.

SEPÚLVEDA, C. A. S. Perfil conceitual de adaptação: uma ferramenta para a análise de discurso de salas de aula de biologia em contextos de ensino de evolução. 2010. $447 f$. Tese (Doutorado em Ensino, Filosofia e História das Ciências) - Instituto de Física, Universidade Federal da Bahia, Salvador, 2010.

SILVA. M. C. F. Pausas em textos orais e espontâneos e em textos falados. Linguagem em discurso, Tubarão, v. 3, n. 1, p. 111-133, jul./dez. 2002.

SILVA, M. P.; NEVES, I. P. Compreender a (in) disciplina na sala de aula: uma análise das relações de controle e poder. Revista Portuguesa de Educação, Braga, v. 19, n. 19, p. 5-41, ago. 2006.

SKOVSMOSE, O. Cenários para Investigação. Bolema, Rio Claro, v. 13, n.14, p. 66-91, 2000.

Submetido em Outubro de 2010. Aprovado em Março de 2012. 